\title{
Natural-resin in-situ-forming gels: Physicochemical characteristics and bioactivities
}

\author{
Ei Mon Khaing1, Torsak Intaraphairot ${ }^{2,3}$, Wichai Santimaleeworagun ${ }^{3,4}$, \\ Yaowalak Phorom ${ }^{5}$, Tiraniti Chuenbarn ${ }^{1}$, Thawatchai Phaechamud ${ }^{1 *}$ \\ 1 Department of Pharmaceutical Technology, Faculty of Pharmacy, Silpakorn University, Nakhon Pathom, Thailand \\ 2 Department of Biopharmacy, Faculty of Pharmacy, Silpakorn University, Nakhon Pathom, Thailand \\ 3 Natural Bioactive and Material for Health Promotion and Drug Delivery System Group (NBM), Faculty of Pharmacy, Silpakorn University, Nakhon \\ Pathom, Thailand \\ 4 Department of Pharmacy, Faculty of Pharmacy, Silpakorn University, Nakhon Pathom, Thailand \\ 5 Office of Secretary, Faculty of Pharmacy, Silpakorn University, Nakhon Pathom, Thailand
}

\begin{abstract}
An injectable in situ-forming gel (ISG) is a promising approach as a drug delivery system. In this study, natural resins including aloe, benzoin and propolis dissolved in $N$-methyl pyrrolidone (NMP) and dimethyl sulfoxide (DMSO) were investigated as ISG systems for their ability to form matrices in phosphate buffer. Regarding their functions as ISG, their $\mathrm{pH}$ values, viscosities, flow behaviours, surface tensions and injectabilities were tested. Benzoin and propolis exhibited greater matrix formation than aloe, owing to their higher resin contents. Benzoin and propolis in DMSO formed matrices with a faster solvent exchange rate compared with those in NMP. The former had a higher viscosity than the latter, but both of them exhibited similar densities and surface tensions. The $35 \%$ and $40 \% \mathrm{w} / \mathrm{w}$ benzoin in DMSO exhibited dominant matrix formations with acceptable injectability via syringe. The 35\% w/w benzoin and propolis ISG in DMSO efficiently inhibited the growth of Staphylococcus aureus strains, and the propolis ISG also exhibited a clear inhibition zone against Porphyromonas gingivalis, whereas aloe did not. From the cell viability assay, propolis exhibited a higher toxicity against HCT116 colon cancer cells $\left(\mathrm{IC}_{50}=95 \mu \mathrm{g} / \mathrm{ml}\right)$ compared with benzoin $\left(\mathrm{IC}_{50}=400 \mu \mathrm{g} / \mathrm{ml}\right)$, whereas the resin from aloe showed no toxic effect on this cell. Due to their rapid insoluble matrix formation after contacting aqueous fluid as well as their antibacterial and cytotoxic activities against colon cancer cell, the $35 \% \mathrm{w} / \mathrm{w}$ benzoin and propolis in DMSO have the potential for use as a matrix former for ISGs.
\end{abstract}

\section{Keywords:}

Natural resin, In situ-forming gel, Bioactivities, Characteristic, Physicochemical

\section{INTRODUCTION}

Over the last decade, injectable in situ-forming gel (ISG) systems have been widely used in the delivery of drugs. ISG is in liquid state before administration and transform into gels in situ within physiological fluid or with environmental stimuli such as solvent exchange, UV-irridation, $\mathrm{pH}$ or temperature change. The solvent exchange-induced ISG comprises a water-insoluble polymer dissolved in biocompatible solvents such as $\mathrm{N}$-methyl-pyrrolidone (NMP) or dimethyl sulfoxide $(\mathrm{DMSO})^{1-3}$. Solvents for ISGs must have properties such as high water affinity, safety and the ability to dissolve both the drug and polymer ${ }^{4}$. Typically, the basic solvents for ISGs are water-miscible liquids, including DMSO and NMP, owing to their low toxicity and suitability for administration via syringe ${ }^{5-6}$. The phase inversion of a dissolved polymer into a semisolid or a solid-like material occurs by the diffusion of an organic solvent into the environment and the diffusion of an aqueous physiological fluid into the system. Various polymers have been investigated for improving of solvent exchange-induced ISG systems ${ }^{7-8}$. Because they are nontoxic, economical, potentially biodegradable and locally

*Corresponding author:

*Thawatchai Phaechamud phaechamud_t@su.ac.th 
available, some natural products such as gums, mucilage and resins have attracted interest for use in drug delivery systems ${ }^{9}$. Bleached shellac, the scarlet resinous secretion of several species of lac insects, has been recently used as a matrix former of ISG systems for periodontitis treatment ${ }^{2,10}$.

Benzoin, a water-insoluble resin obtained from styrax species, has been widely used in perfume, antiseptic and topical adhesive agents. The major constituents of benzoin resin are conifeyl benzoate, benzoic acid, cinnamic acid and p-carmaryl cinnamate, as well as triterpenoids as minor compounds ${ }^{11}$. These components exhibit antibacterial and antioxidant activities ${ }^{12}$. Propolis collected by bees from plant resins has been used as a traditional medicine for centuries. Typically, the compounds found in propolis include polyphenol, phenolic aldehydes, ketones, ascorbic acid and some organic compounds ${ }^{13}$. Propolis has been utilised for a wide range of biological applications, including antibacterial, antioxidant, anti-inflammatory, antiviral, anticancer and antitumor ${ }^{14}$. Moreover, it has been used as a lipid material in the preparation of solid lipid nanoparticles comprising diclofenac for intranasal delivery ${ }^{15}$. Aloe resin is a solid residue obtained by transversely cutting the leaf of aloe ferox ${ }^{16}$. The middle latex layer in an aloe leaf comprises various metabolites, including glycosylated anthrones (up to $35 \%$ aloin A and aloin B), glycosylated chromones (aloesin and aloeresin), glycosylated anthraquinones and polyphenols ${ }^{17}$. Various compounds that have been isolated from aloes are used in pharmaceutical applications, such as anti-inflammatory treatments ${ }^{18}$, antimicrobial activity ${ }^{19}$ and antioxidant effects ${ }^{20}$.

Some natural resins can dissolve in NMP and DMSO; therefore, the aim of this study was to prepare aloe, benzoin and propolis ISG systems and then investigate their properties including $\mathrm{pH}$, viscosity, rheology, injectability, gel formation and antimicrobial activities. The MTT assay was performed to determine the cytotoxic effect of the natural-resin ISG systems on HCT116 colon cancer cells. The MTT assay is a colorimetric assay for assessing cell metabolic activity. The enzymes of cell are capable of reducing the tetrazolium dye MTT (3-(4,5-dimethylthiazol-2-yl)2,5-diphenyltetrazolium bromide) to its insoluble formazan, which has a purple color.

\section{MATERIALS AND METHODS}

\subsection{Materials}

Propolis was purchased from Bee Product Industry Co., Ltd., Chiang Mai, Thailand, while aloe and benzoin were purchased from the Kanchana Crude Drug store, Nakhon Pathom, Thailand and DMSO (lot no.453035, Fluka, Switzerland) and NMP (lot
no.A0251390, Fluka, New Jersey, USA) were used as received. Mitis Salivarius agar (lot no.0118681), tryptic soy broth (lot no. 8091999) and tryptic soy agar (lot no.7341698), from Difco, USA, as well as brain heart infusion (lot no.0270845) and brain heart infusion agar (lot no.0298038), from Bacto ${ }^{\mathrm{TM}}$, USA, were used as media for the antimicrobial tests. Phosphate-buffered saline (PBS) pH 6.8 was used to simulate gingival crevicular fluid $^{21}$. The antimicrobial susceptibility test disc, ampicillin $10 \mu \mathrm{g} / \mathrm{disc}$ (Becton Dickinson \& Company, USA), was used as the positive control for the antibacterial tests. Moreover, HCT116 colorectal carcinoma cell line from the American Type Culture Collection (ATCC), USA, was used to determine the cytotoxic activity of the resins. The culture medium components, including fetal bovine serum, L-glutamine, DMEM, penicillin and streptomycin, were purchased from Invitrogen, Paisley, UK.

\subsection{ISG preparation}

The ISG systems were prepared using different concentrations of natural resins $(25,30,35,40,45$, and $50 \% \mathrm{w} / \mathrm{w}$ ) dissolved in NMP and DMSO, and they were stirred for $24 \mathrm{~h}$ at room temperature before evaluation.

\subsection{Physical appearance, $\mathrm{pH}$ and density}

The $\mathrm{pH}$ values of the prepared resin ISG systems were determined using a $\mathrm{pH}$ meter (Ultra Basic UB-10, Denver Instrument, Bohemia, New York) $(\mathrm{n}=3)$, and their density values were measured using a pycnometer (Densito 30PX, Mettler Toledo (Thailand) Ltd, Portable Lab TM) (triplicate testing; $n=3$ ).

\subsection{In vitro gel formation}

The formation of the gel or solid-like resin matrix was observed by injecting $0.5 \mathrm{ml}$ of resin ISG in different solvents via an 18-gauge needle into transparent glass test tubes containing a $5 \mathrm{ml}$ PBS pH 6.8. The gel formation of the prepared resin ISG systems was photographed at various times $(0,1,5$ and $30 \mathrm{~min})$.

\subsection{Viscosity and rheological behaviour studies}

The apparent viscosity and stress rate/shear stress curves of the resin ISG systems were measured using a Brookfield DV-III Ultra programmable rheometer (Brookfield Engineering Laboratories Inc, Middleboro, MA, USA) in triplicate. The flow parameters were determined using an exponential equation in which $\mathrm{N}$ is the exponential constant (Farrow's constant) and $\eta^{\prime}$ is the viscosity coefficient, as method previously reported by ${ }^{22}$. 


\subsection{Injectability test}

The injectability was determined using a texture analyser in compression mode (TA.XT plus, Stable Micro Systems, UK) to gauge the ease of administering the prepared ISG via injection by needle, as previously described by ${ }^{23}$. The resin ISG was inserted into a $1 \mathrm{ml}$ syringe with a 27 -gauge needle that was clamped to a stainless stand. Then, the upper probe of the texture analyser was moved downwards at a constant speed $\left(1.0 \mathrm{~mm} \mathrm{~s}^{-1}\right)$ while applying a constant force of $0.1 \mathrm{~N}$ to the base, and this force at a distance of 10 $\mathrm{mm}$ was used for the analysis. The expulsive force was determined based on the area under the resulting curve, with a lower force required for injection signifying good injectability. This measurement was performed in triplicate for each system.

\subsection{Surface tension study}

The surface tension of the prepared resin ISG systems was determined using the drop-shape analysis method and a goniometer (FTA 1000, First Ten Angstroms, USA) (pump-out rate $2.58 \mathrm{ul} / \mathrm{s})(\mathrm{n}=6)$.

\subsection{Rate of matrix formation}

The resin matrix occurred due to the phase separation of the aqueous insoluble resin during solvent exchange. The water diffusion rate into the prepared systems was determined by measuring the distance of the change from a sol into a turbid gel or matrix phase in an agarose gel $(0.6 \%$ agarose dispersed in PBS pH 6.8). This test was conducted by adding $150 \mu \mathrm{L}$ resin ISG systems into a $6 \mathrm{~mm}$ diameter agarose well and taking a photograph with a stereo microscope (Motic SMZ-171 Series). The water diffusion distance was measured in triplicate based on the visible change in the system from transparent to opaque as the water diffused into the system, recording observations every $5 \mathrm{~min}$ for $30 \mathrm{~min}$, and the diffusion rate was calculated.

\subsection{Antimicrobial activity studies}

Agar-cup diffusion method was employed to test the antimicrobial activity of the prepared ISG systems against standard microbes (Staphylococcus aureus, Escherichia coli and Candida albicans), other strains of Staphylococcus aureus (S. aureus ATCC 25923, S. aureus DMST 6903 and S. aureus ATCC43300) and Porphyromonas gingivalis ATCC 33277. For $P$. gingivalis, the antibacterial test was conducted using an anaerobic incubator (Forma Anaerobic System, Thermo Scientific, Ohio, USA), as previously described ${ }^{2}$. The turbidity of the microbes was adjusted with $0.5 \mathrm{McFarland}$ standard. Then, the obtained inoculate was thoroughly plated on agar. Afterwards, $100 \mu \mathrm{L}$ of ISG was filled into a stainless cup, which was placed on the surface of this inoculated agar plate. The prepared plates were then incubated at $35^{\circ} \mathrm{C}$ for $24-48 \mathrm{~h}$. An inhibition zone margin of some millimetres was detected with the unaided eye. All tests were performed in triplicate.

\subsection{Determination of cytotoxic activity}

Cell line HCT116 was cultured in DMEM $4.5 \mathrm{~g} / 1$ glucose supplemented with $1 \%$ glutamine, $10 \%$ heatinactivated fetal bovine serum, $5 \mu \mathrm{G} / \mathrm{ml}$ streptomycin and $150 \mathrm{U} / \mathrm{ml}$ penicillin and was incubated in a humidified incubator at $37^{\circ} \mathrm{C}, 5 \% \mathrm{CO}_{2}$. For MTT assay using colorectal HCT 116 cell line, three independent passages of HCT116 were seeded at a density of 10,000 cells/well in $100 \mu \mathrm{l}$ medium in a 96-well plate. Twentyfour hours after seeding, the culture medium was changed to a $100 \mu \mathrm{l}$ medium containing 0 to $800 \mu \mathrm{g} / \mathrm{ml}$ resin prepared from $35 \% \mathrm{w} / \mathrm{w}$ three resins in DMSO with serial dilution. The medium was employed as a control group. After $72 \mathrm{~h}$ incubation, the viability of each well was determined by adding $10 \mu \mathrm{l}$ MTT and further incubating at $37^{\circ} \mathrm{C}$ for $3 \mathrm{~h}$. After the incubation, the medium was gently removed, and $100 \mu$ of DMSO was mixed into each well, and the absorbance was measured by a microplate reader at $550 \mathrm{~nm}$. The toxic concentrations of solvents were determined and compared (repetition testing with a sample size of $n=9$ ). To investigate the cell viability of the compounds released from the resin, $1 \mathrm{~g}$ of ISG was inserted into a dialysis tube (Spectra/Por, molecular weight cutoff: 6,000-8,000) and immersed into $100 \mathrm{ml}$ of $\mathrm{PBS} \mathrm{pH} 6.8$ at $37^{\circ} \mathrm{C}$ at a rotational speed of $50 \mathrm{rpm}$. Then, $10 \mathrm{ml}$ aliquots from the release medium were withdrawn at different time intervals and replaced with $10 \mathrm{ml}$ of fresh medium. The obtained release medium was tested for cell viability using the method described above.

\subsection{Statistical analysis}

The statistical significance of the obtained data was determined using one-way analysis of variance, followed by a least-significant-difference post-hoc test. The significance level was set at $\mathrm{P}<0.05$, and the analysis was performed using SPSS software for Windows (version 11.5).

\section{RESULTS AND DISCUSSION}

\subsection{Physical appearance, $\mathrm{pH}$ and density}

The resin solutions in NMP and DMSO were yellowish, and their $\mathrm{pH}$ and density data are presented in Figure 1. The $\mathrm{pH}$ values decreased with an increasing concentration of resins in both solvents owing to the 
presence of an acidic group, such as carboxylic acid, in the components of benzoin ${ }^{24}$ and propolis ${ }^{25}$. The $\mathrm{pH}$ values of all the ISG systems ranged between 5.386 and 7.197. The $\mathrm{pH}$ test results were close to neutral, which indicates that the formulations were compatible for application to body fluids or human tissues. The density of the prepared systems slightly increased when the resin amount was increased in the solvents. The density of a substance is the ratio of its mass to its volume, which is related to its apparent viscosity ${ }^{26}$. Aloe ISG systems showed a higher density than the benzoin and propolis ISG systems. The densities of the resins in DMSO were slightly higher than those in NMP due to the lower density of $\mathrm{NMP}^{27}$.

\subsection{In vitro gel formation}

Figure 2 shows the matrix formations of the benzoin and propolis ISG systems. The ISGs became more matrix-like mass as the concentration of resin increased from $25-50 \%$. However, the $25 \%-35 \%$ benzoin and $25 \%$ of propolis in NMP did not form into a gel after injection into PBS. The use of lesser amounts of resins in organic solvents did not result in a sudden matrix formation from phase separation. In contrast, increasing the resin ratio resulted in a rapid transformation into a matrix. The transformation characteristics that depend on the polymer concentration in polymer-based ISGs have been previously described ${ }^{22}$. Moreover, rapid gel formation was evident for the resin ISG systems using DMSO as the solvent. The solvent polarity might affect the gelling properties of a polymer in buffer solutions, and the polarity of DMSO is higher than that of $\mathrm{NMP}^{2}$. Therefore, DMSO could rapidly diffuse into water and influence a solvent exchange within one minute. Aloe showed an insufficient matrix formation (data not shown) because of its low content of aqueous insoluble resin. Only $16 \%$ aloin and Cape aloe occurred as the main resins in aloe from plant extract ${ }^{16}$, whereas $50 \%$ resin in propolis ${ }^{14,28}$ and $90 \%$ benzoin resin have been reported in the stems of Styrax officinalis ${ }^{29}$.
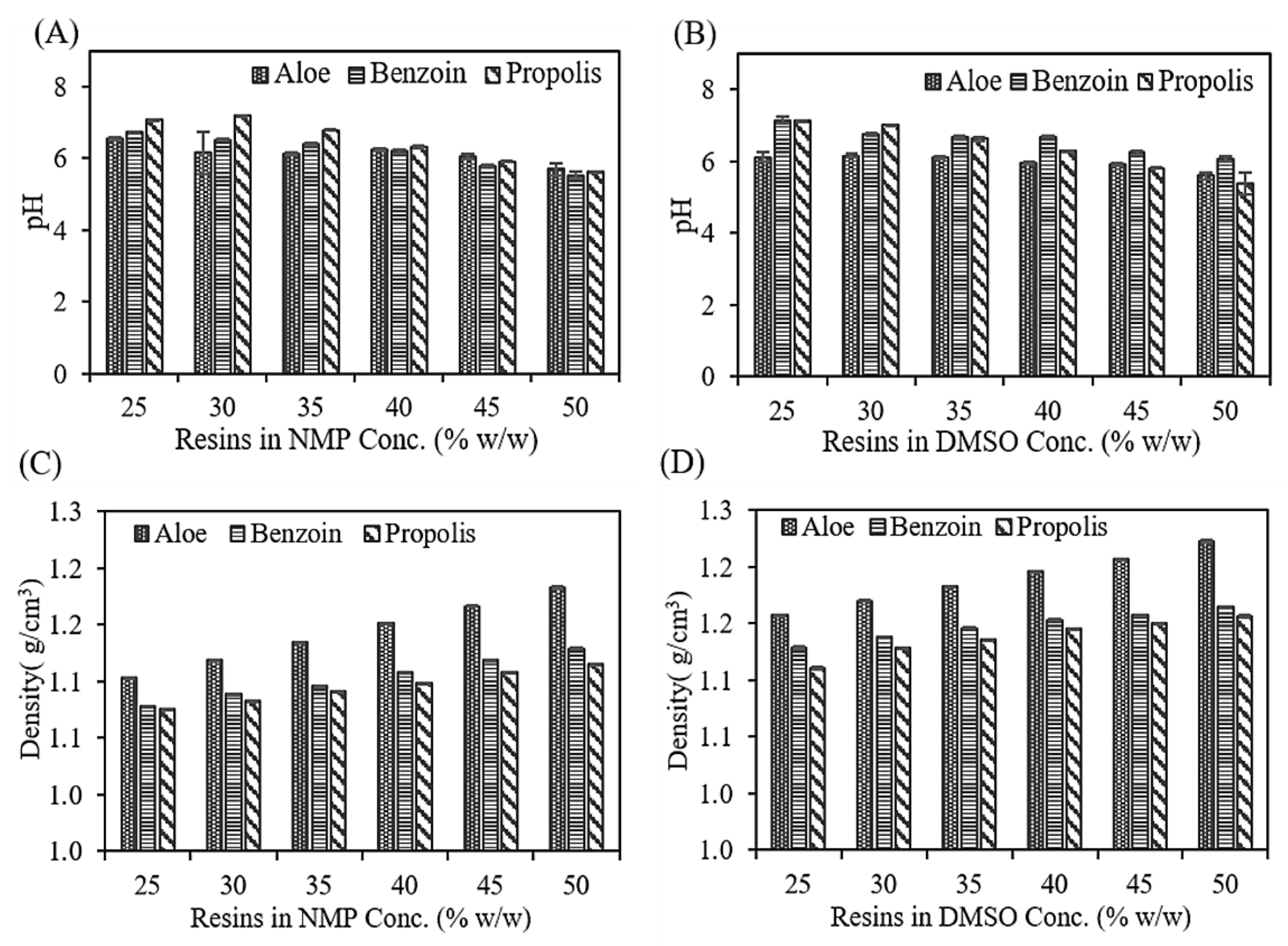

Figure 1. $\mathrm{pH}$ and density of aloe, benzoin and propolis ISG systems in NMP (A, C) and DMSO (B, D). The data represent the mean ( \pm S.D.) of three replicates. 


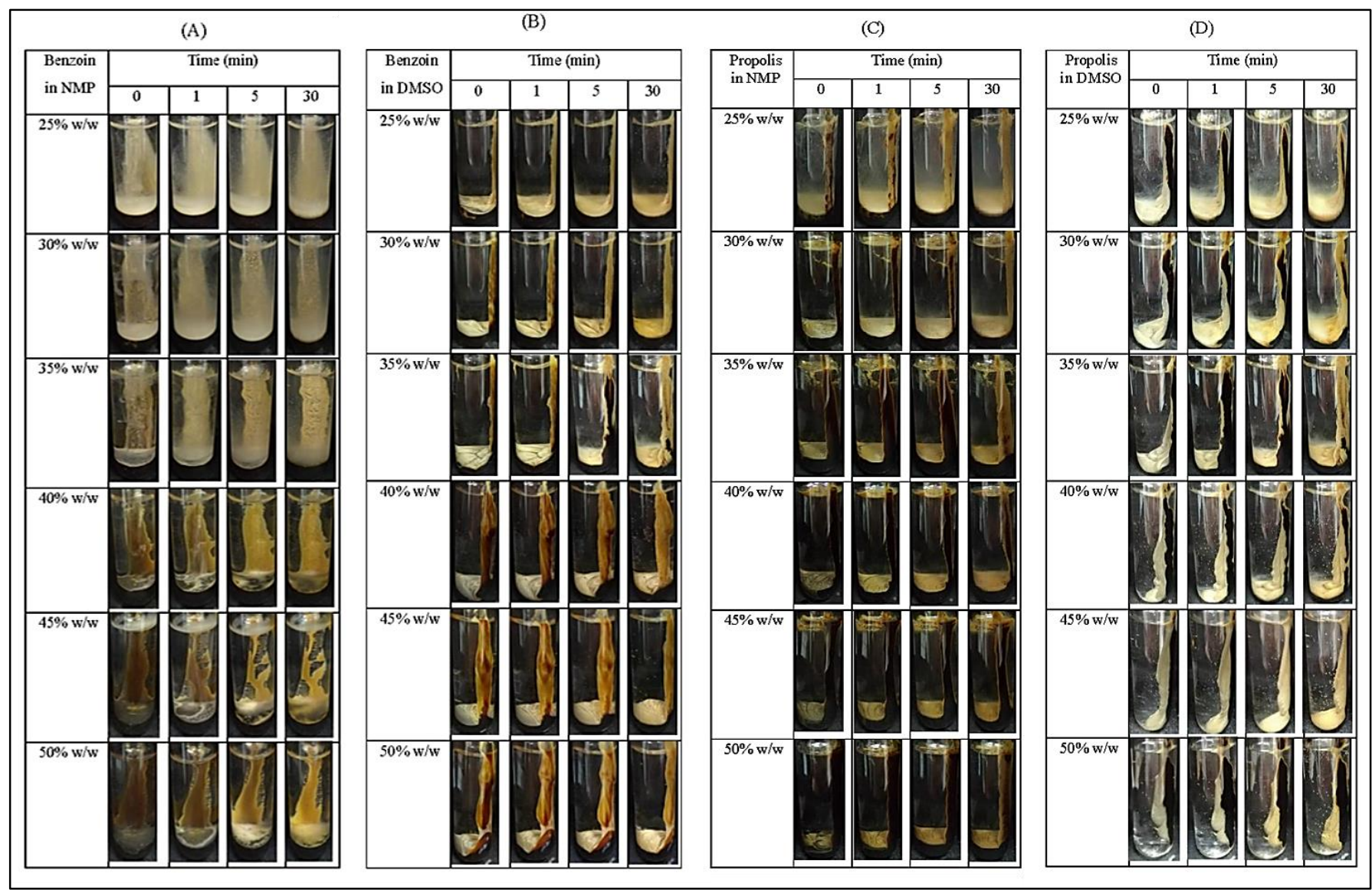

Figure 2. Matrix formation of benzoin ISG systems in NMP (A) and DMSO (B) and propolis in NMP (C) and DMSO (D) after injection in PBS (pH 6.8) at different times.

\subsection{Viscosity and rheological behaviours}

Table 1 presents the viscosities and flow indexes of the resin ISG systems in NMP and DMSO, in which a high resin concentration promoted a more viscous environment for which their viscosities also significantly increased, especially at $50 \% \mathrm{w} / \mathrm{w}(P<0.05)$. Viscosity is an internal property of a fluid affecting many ISG properties based on the solvent exchange mechanism. The viscous nature of semisolid delivery systems typically retards the diffusion rate as well as the penetration of the drug molecule and solvent. A suitable solvent must enhance the solvent-substance interactions required for promoting a high amount of drug dissolution $^{30}$. Benzoin and propolis dissolved in DMSO featured higher viscosities compared to when in NMP due to the DMSO higher viscosity. However, the viscosity of aloe in NMP was higher than that of aloe in DMSO. The resin in aloe dissolved not quite completely in NMP, thus increasing the viscosity of aloe in NMP. The viscosities of $25 \%-50 \% \mathrm{w} / \mathrm{w}$ benzoin in NMP and DMSO were $6.61-171.46 \mathrm{cP}$ and $19.77-137.03 \mathrm{cP}$ as compared to propolis, $11.91-155.60 \mathrm{cP}$ and $80.96-577.90 \mathrm{cP}$, respectively. The resin concentrations less than $40 \%$ ISG systems could be easily administered via injection because their viscosities were lower than the viscosity threshold for the injection of $300 \mathrm{cP}^{31}$. Typically, a higher viscosity in concentrated solutions requires a higher injectable force. The resins with appropriate concentrations of $35 \%$ and $40 \% \mathrm{w} / \mathrm{w}$ were selected for further investigation. The flows of ISGs comprising benzoin and aloe were Newtonian because their exponent constant was close to 1 . Newtonian fluids with shear stress that is independent of the shear rate have an $n$ value close to $1^{32}$. In contrast, the propolis ISG system had an $\mathrm{n}$ value less than 1, which indicates shear thinning or pseudoplastic behaviour. The flow behaviour must be either Newtonian or pseudoplastic for ease of injection ${ }^{33}$.

\subsection{Injectability and surface tension}

When developing ISG systems, injectability into the target site is a crucial consideration. Normally, injectability involves the pressure or force required for injection, the flow smoothness and the absence of any blockage from the syringe needle ${ }^{34}$. Typically, a linear relationship exists between the force required for injection and the viscosity of the formulation being injected ${ }^{35}$. If the viscosity value is very high, there is difficulty with injection. The aloe ISGs and propolis in DMSO ISGs were not tested for injectability owing their too high viscosity and inability to extrude through the needle. The $35 \%-40 \% \mathrm{w} / \mathrm{w}$ propolis and benzoin were 
selected for this investigation because of their appropriate viscosity with rather high resin concentration for enough matrix formation. The forces required to inject benzoin dissolved in NMP and DMSO were similar (Table 2). All formulations had an acceptable injection force lower than $50 \mathrm{~N}^{35}$. The surface tensions of the benzoin and propolis ISG systems were lower than those of their solvents because the dissolved resins reduced the cohesive forces, such as the hydrogen bonding of solvent molecules (Table 2). The low surface tension values of these ISG systems indicated that they could spread onto a contact surface ${ }^{36}$. The surface tension of propolis in DMSO was not determined because of the high viscosity.

\subsection{Matrix formation rate}

The resin matrix formation of the prepared ISG systems occurred due to the water influx and solvent efflux $^{37}$. This solvent exchange occurred when the PBS medium in agarose diffused into the ISG and the solvent in the ISG diffused into agarose-containing PBS. Immediately, the precipitated resin appeared as an opaque ring of resin matrix from the outer rim expanding into the inner well. The diffusion rate of environmental aqueous of agarose gel inducing resin matrix formation was higher in the case of the $35 \%$ and $40 \% \mathrm{w} / \mathrm{w}$ benzoin ISGs in DMSO than that of in NMP (Figure 3A) due to the strong water miscibility of DMSO. Their matrix formation distances are presented in Figure 3B. DMSO diffuses rapidly through aqueous environments when in contact with the aqueous environment. The resin in NMP took a longer time to become opaque during matrix formation than that in DMSO because NMP is less water-miscible. The solubility parameters of DMSO and NMP have been reported to be $26.7(\mathrm{~J} / \mathrm{cm} 3)^{1 / 2}$ and $23.2(\mathrm{~J} / \mathrm{cm} 3)^{1 / 2}$, respectively, ${ }^{6}$. Solvents with high water affinities increase the phase separation rate ${ }^{4}$. The matrix formation rate significantly decreased for all systems at $30 \mathrm{~min}$. A high formation rate was observed within $5 \mathrm{~min}$ in the highest-concentrated-resin ISG system in DMSO, and it decreased slightly with time due to the dense resin matrix network and phase-transition equilibrium ${ }^{3}$.

\subsection{Antimicrobial activities}

The $35 \% \mathrm{w} / \mathrm{w}$ benzoin, propolis and aloe ISG systems using DMSO as a solvent were tested for their antimicrobial activities against different microbes. The inhibition zone diameters of the control group (DMSO) against $S$. aureus, E. coli and C. albicans were 10.5 \pm 1.3 , $12.5 \pm 0.4$ and $17.8 \pm 0.8 \mathrm{~mm}$, respectively, and (Table 3 ). However, the control group. The high solubility of DMSO enables it to penetrate cell membranes by reducing the cell division rate in bacterial cells ${ }^{38}$. In contrast, the resin ISG systems did not inhibit $E$. coli because the cell wall of Gram-negative bacteria is more complex and has a higher lipid concentration to retard drug penetration ${ }^{39}$. The inhibitory effect of benzoin against $C$. albicans was significantly higher than that of propolis $(P<0.05)$, whereas they had similar inhibitionclear-zone diameters for the $S$. aureus strains. The propolis and benzoin ISG systems showed antimicrobial activities that inhibited the growth of three Staphylococcus aureus strains (S. aureus ATCC25923, S. aureus ATCC43300 and $S$. aureus DMST 6903), but only the propolis ISG inhibited $P$. gingivalis (the major Gramnegative anaerobic bacteria of chronic periodontitis). The aloe ISG had a slight antimicrobial effect only on $S$. aureus. The isolated compounds, namely aloe-emodin and aloin from aloe excelsa leaves, demonstrated antibacterial activity against Gram-positive and Gramnegative bacterial strains, including $S$. aureus ${ }^{19}$. Benzoin resin containing an isolated compound such as an essential oil can reportedly inhibit Gram-positive $S$. aureus and Gram-negative E. coli ${ }^{12}$. The presence of considerable numbers of the flavonoids and esters of phenolic acids in propolis are responsible for its antibacterial activities ${ }^{40-42}$. Dentifrice-containing propolis has been reported to reduce contamination by the standard $S$. mutans strain on toothbrush bristles ${ }^{43}$. Inhibition against $C$. albicans ${ }^{44}$ and $S$. aureus ${ }^{45}$ by propolis has also been reported. Furthermore, owing to its antimicrobial activity, propolis with metronidazole microparticles based on methylcellulose has been reported to enhance antimicrobial synergism for periodontal treatment, compared with metronidazole ${ }^{46}$. From the above results, the antimicrobial activities of benzoin and propolis ISG systems are attractive for use in the delivery of antimicrobial agents, particularly for the treatment of periodontitis.

\subsection{Cytotoxicity assay}

In the MTT assay, propolis and benzoin ISG systems in DMSO showed toxicity to HCT116 colon cancer cell (Figure 4). The aloe exhibited no toxic effect on this cancer cell line. Some researchers have reported that extract compounds from dried exudates of aloe had no significant cytotoxicity on HepG2 cells ${ }^{18}$. However, propolis showed a higher toxicity $\left(\mathrm{IC}_{50}=95 \mu \mathrm{g} / \mathrm{ml}\right)$ than benzoin $\left(\mathrm{IC}_{50} 400 \mu \mathrm{g} / \mathrm{ml}\right)$. Propolis extracts from the stingless bee Trigona pagdeni showed toxicity against four human cancer cell lines (KB, HepG2, Caco-2 and SK-MEL-28) with IC50 values ranging from $33.38 \mu \mathrm{g} / \mathrm{ml}$ to $80.81 \mu \mathrm{g} / \mathrm{ml}$, owing to the presence of the active compound of mangostine ${ }^{47}$. Dichloromethane extracts of propolis from the Trigona sirindhornae bee have demonstrated cytotoxic activities to head and neck squamous cell carcinoma cell lines ${ }^{48}$. These results reveal that propolis and benzoin ISG systems exhibited anticancer activity. Owing to the interesting decreased 
cell viability of benzoin, the MTT test for the release medium from benzoin ISG was conducted at different time points after the release test; the percentage cell viability decreased from $21.3 \%$ (after $1 \mathrm{~h}$ release) to $11.7 \%$ (after $72 \mathrm{~h}$ release) (Figure 5). Thus, this cytotoxicity might be due to the compound liberated from benzoin ISG which could inhibit HCT116. The isolated triterpenoids compounds in benzoin resin have also been reported to show toxicity against HL-60 cell growth, with $\mathrm{IC}_{50}$ values ranging from $4.03 \mu \mathrm{g} / \mathrm{ml}$ to 48.37 $\mu \mathrm{g} / \mathrm{ml}^{49}$.

\section{CONCLUSION}

In this study, natural-resin ISG systems were prepared by dissolving benzoin, aloe and propolis in NMP and DMSO. Propolis and benzoin in DMSO transformed into a matrix in PBS more rapidly than those

Table 1. Viscosity and flow index of aloe, benzoin and propolis ISG systems in NMP and DMSO solvents.

\begin{tabular}{|c|c|c|c|c|c|}
\hline \multirow[t]{2}{*}{ Resin } & \multirow{2}{*}{$\begin{array}{c}\text { Conc. } \\
(\% \mathrm{w} / \mathrm{w})\end{array}$} & \multicolumn{2}{|c|}{ Viscosity (cP) } & \multicolumn{2}{|c|}{ Flow index (n) } \\
\hline & & in NMP & in DMSO & in NMP & in DMSO \\
\hline \multirow[t]{6}{*}{ Aloe } & 25 & $15.88 \pm 0.00$ & $8.48 \pm 0.43$ & $0.74 \pm 0.01$ & $1.28 \pm 0.08$ \\
\hline & 30 & $28.84 \pm 0.70$ & $21.56 \pm 0.61$ & $0.98 \pm 0.05$ & $0.95 \pm 0.08$ \\
\hline & 35 & $59.26 \pm 0.46$ & $38.62 \pm 0.46$ & $0.97 \pm 0.00$ & $1.02 \pm 0.02$ \\
\hline & 40 & $135.96 \pm 0.46$ & $73.56 \pm 0.46$ & $0.91 \pm 0.01$ & $1.01 \pm 0.01$ \\
\hline & 45 & $336.83 \pm 1.17$ & $160.03 \pm 0.46$ & $0.96 \pm 0.03$ & $0.79 \pm 0.19$ \\
\hline & 50 & $765.46 \pm 1.22 *$ & $366.17 \pm 0.46^{\mathrm{a}}$ & $0.98 \pm 0.00$ & $0.99 \pm 0.01$ \\
\hline \multirow[t]{6}{*}{ Benzoin } & 25 & $6.61 \pm 0.46$ & $19.77 \pm 0.46$ & $1.55 \pm 0.05$ & $0.86 \pm 0.03$ \\
\hline & 30 & $13.76 \pm 0.46$ & $27.78 \pm 0.00$ & $1.13 \pm 0.02$ & $0.96 \pm 0.01$ \\
\hline & 35 & $24.78 \pm 0.46$ & $31.62 \pm 0.40$ & $0.96 \pm 0.04$ & $0.16 \pm 0.05$ \\
\hline & 40 & $40.48 \pm 0.00$ & $62.71 \pm 0.80$ & $1.10 \pm 0.03$ & $0.93 \pm 0.04$ \\
\hline & 45 & $81.22 \pm 0.46$ & $80.96 \pm 0.80$ & $0.92 \pm 0.01$ & $1.04 \pm 0.03$ \\
\hline & 50 & $171.46 \pm 0.75^{* *}$ & $137.03 \pm 0.46^{\mathrm{b}}$ & $0.94 \pm 0.01$ & $1.13 \pm 0.00$ \\
\hline \multirow[t]{6}{*}{ Propolis } & 25 & $11.91 \pm 0.00$ & $80.96 \pm 1.59$ & $0.36 \pm 0.10$ & $0.58 \pm 0.02$ \\
\hline & 30 & $22.76 \pm 0.46$ & $121.93 \pm 0.92$ & $0.35 \pm 0.02$ & $0.55 \pm 0.03$ \\
\hline & 35 & $40.22 \pm 0.46$ & $173.53 \pm 0.49$ & $0.46 \pm 0.05$ & $0.51 \pm 0.10$ \\
\hline & 40 & $57.68 \pm 1.21$ & $234.20 \pm 0.80$ & $0.60 \pm 0.03$ & $0.43 \pm 0.04$ \\
\hline & 45 & $104.80 \pm 1.39$ & $387.10 \pm 2.39$ & $0.66 \pm 0.08$ & $0.39 \pm 0.04$ \\
\hline & 50 & $155.60 \pm 0.00 * * *$ & $577.90 \pm 0.80^{c}$ & $0.90 \pm 0.00$ & $0.34 \pm 0.01$ \\
\hline
\end{tabular}

The data represent the mean ( \pm S.D.) of three replicates.

The asterisks $(*, * *, * *)$ and superscript $\mathrm{a}, \mathrm{b}$ and $\mathrm{c}$ represent a significant difference $(P<0.05)$

Table 2. Injectabilities $(n=3)$ and surface tensions $(n=6)$ of benzoin and propolis ISG systems $(n=3)$. All data represent mean values $( \pm$ S.D.).

\begin{tabular}{|c|c|c|c|c|}
\hline \multirow[t]{2}{*}{ Formula } & \multirow{2}{*}{$\begin{array}{c}\text { Conc. } \\
(\% \text { w/w) }\end{array}$} & \multicolumn{2}{|c|}{ Injectability } & \multirow[t]{2}{*}{$\begin{array}{l}\text { Surface tension } \\
\quad(\mathrm{mN} / \mathrm{m})\end{array}$} \\
\hline & & Force (N) & Work (N.mm) & \\
\hline \multirow[t]{2}{*}{ Benzoin in NMP } & 35 & $0.786 \pm 0.069$ & $1.462 \pm 0.098$ & $40.98 \pm 0.23$ \\
\hline & 40 & $1.027 \pm 0.084$ & $2.808 \pm 0.367$ & $41.81 \pm 0.02$ \\
\hline \multirow[t]{2}{*}{ Benzoin in DMSO } & 35 & $0.723 \pm 0.076$ & $1.786 \pm 0.445$ & $40.26 \pm 0.08$ \\
\hline & 40 & $1.120 \pm 0.165$ & $3.297 \pm 0.622$ & $39.75 \pm 0.10$ \\
\hline \multirow[t]{2}{*}{ Propolis in NMP } & 35 & $0.963 \pm 0.118$ & $1.900 \pm 0.529$ & $35.95 \pm 0.50$ \\
\hline & 40 & $4.330 \pm 0.290$ & $37.624 \pm 1.927$ & $34.95 \pm 0.25$ \\
\hline
\end{tabular}

Table 3. Antimicrobial activities of aloe, propolis and benzoin ISG systems against different microbes $(n=3)$.

\begin{tabular}{|c|c|c|c|c|c|c|c|}
\hline \multirow{3}{*}{$\begin{array}{l}\text { Formula } \\
(35 \% w / w)\end{array}$} & \multicolumn{7}{|c|}{ Clear zone dimeter $(\mathrm{mm}).($ mean \pm S.D. $)$} \\
\hline & S. aureus & E. coli & C. albicans & P. gingivalis & S. aureus & S. aureus & S. aureus \\
\hline & & & & & ATCC 25923 & ATCC 43300 & DMST 6903 \\
\hline Aloe & $7.50 \pm 0.40$ & - & - & - & - & - & - \\
\hline Propolis & $11.50 \pm 0.90$ & - & $13.70 \pm 1.20$ & $25.67 \pm 0.57$ & $12.00 \pm 0.00$ & $8.00 \pm 0.00$ & $8.00 \pm 0.00$ \\
\hline Benzoin & $11.00 \pm 0.06$ & - & $21.00 \pm 1.70$ & - & $12.00 \pm 0.00$ & $10.00 \pm 0.00$ & $8.00 \pm 0.00$ \\
\hline DMSO & $10.50 \pm 1.30$ & $12.50 \pm 0.50$ & $17.80 \pm 0.80$ & - & - & - & - \\
\hline
\end{tabular}




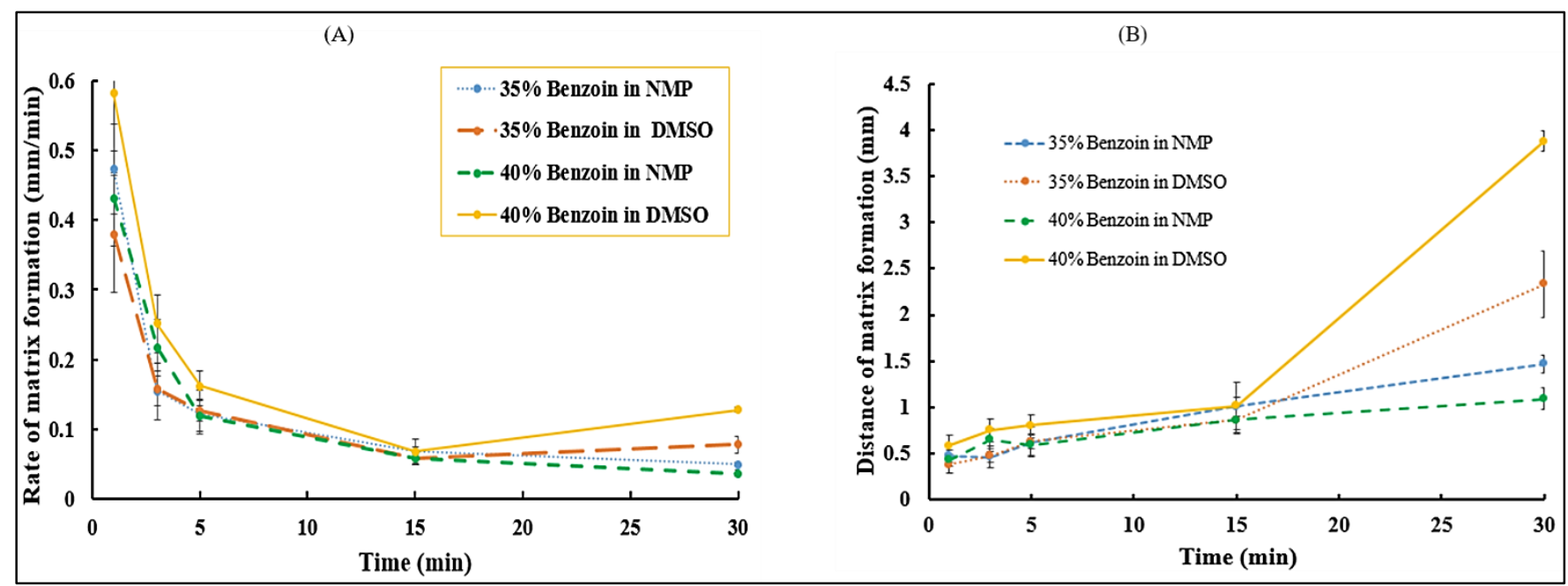

Figure 3. Matrix formation rate (A) and matrix formation distance (B) of benzoin in NMP and DMSO at different time intervals ( $\mathrm{n}=3$ ).

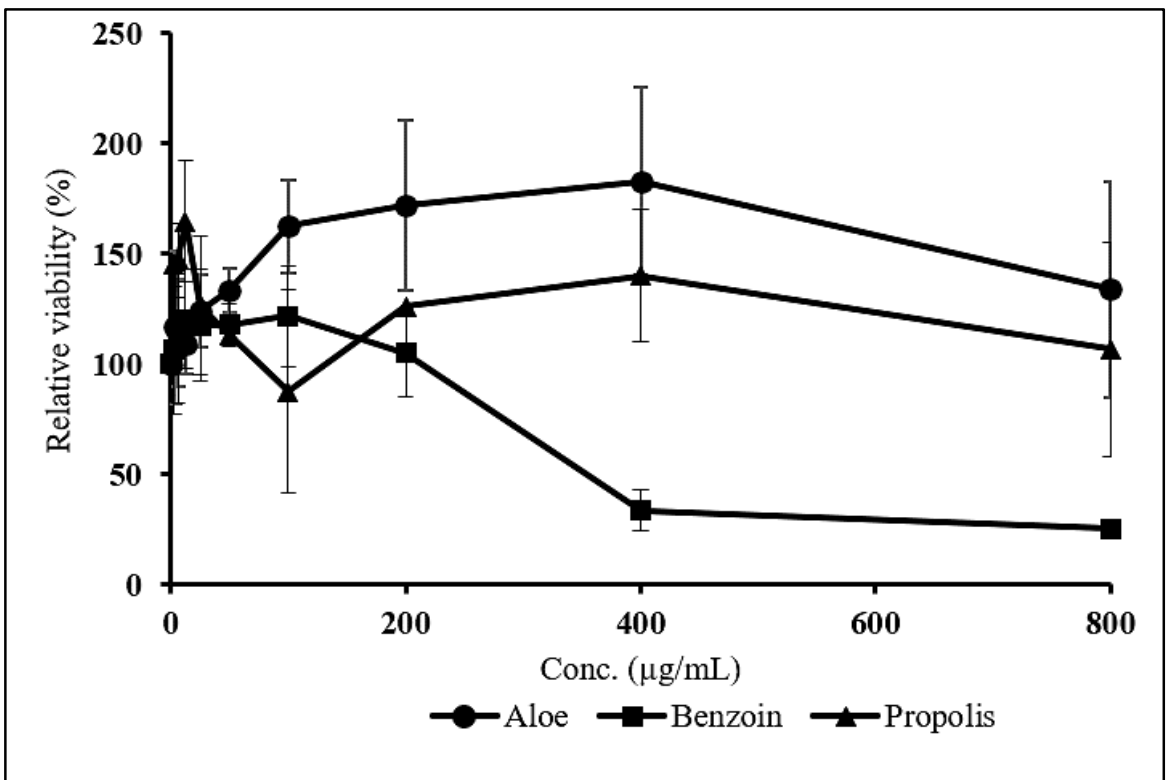

Figure 4. Relative viability (\%) with concentrations of aloe, benzoin and propolis on HCT 116 cell line.

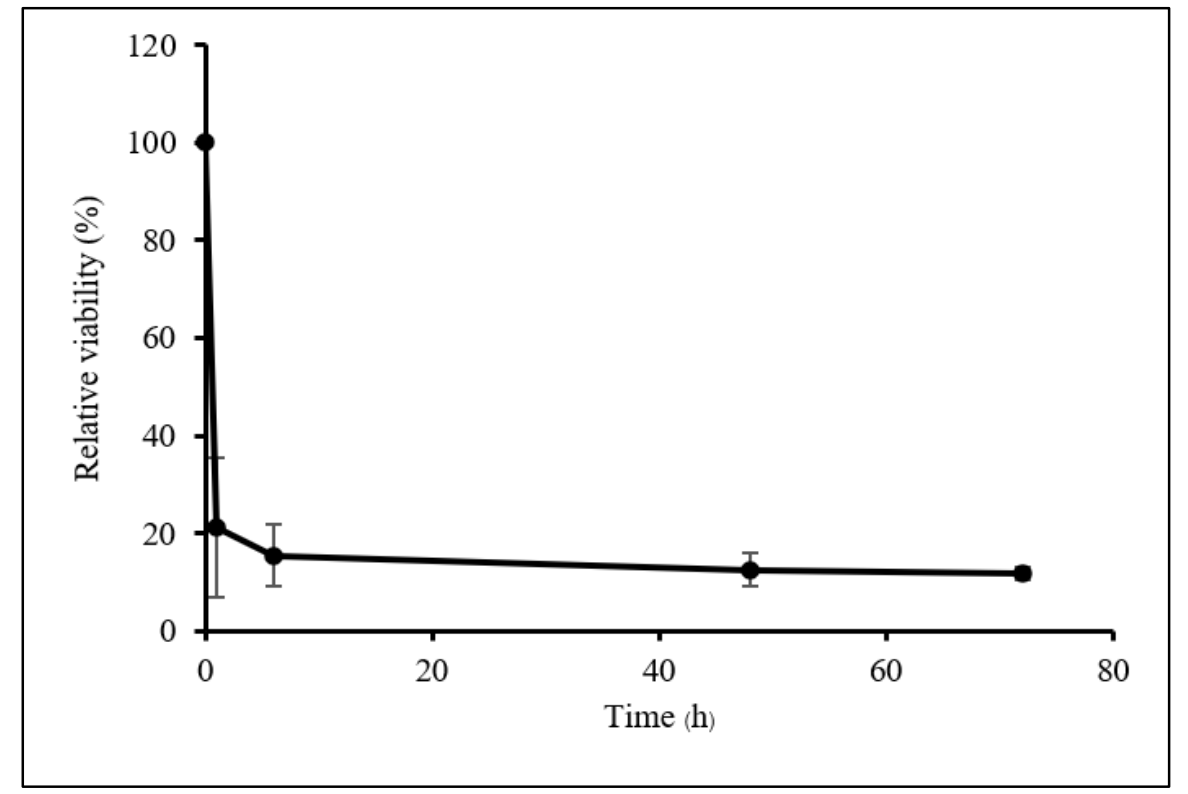

Figure 5. Relative viability (\%) with released samples from $40 \% \mathrm{w} / \mathrm{w}$ benzoin at different time intervals $(\mathrm{n}=3)$. 
prepared with NMP, whereas aloe in these solvents did not transform into a resin matrix in PBS. The $35-40 \%$ $\mathrm{w} / \mathrm{w}$ concentration of benzoin and propolis systems presented suitable properties with their low viscosities, good injectabilities and ability to form gels. The 35\% propolis and benzoin in DMSO demonstrated antimicrobial activity and cytotoxicity against colon cancer cell. The in vitro gel formation and matrix formation rates indicate that propolis and benzoin have good potential as matrix formers, which can be incorporated with active compounds such as anticancer drugs or antimicrobial drugs, and the formed product may provide a treatment effect complementary to that of the main drugs.

\section{ACKNOWLEDGEMENT}

The researchers are grateful to the Research and Creative Fund, Faculty of Pharmacy, Silpakorn University, Thailand. We also thank Paul Mines for his proof reading. Natchapol Intasorn, Siripong Srisukha and Supanat Pongaree are acknowledged for their valuable comments and help. We also thank "Natural bioactive and material for health promotion and drug delivery system" team, Faculty of Pharmacy, Silpakorn University for all contributions.

\section{Conflict of interest}

The authors report no conflicts of interest in this work.

\section{Funding}

The authors declare that they have no conflict of interest with this investigation.

\section{Ethics approval}

This article does not contain any studies with human or animal subjects performed by any of the authors.

\section{Article info:}

Received May 12, 2020

Received in revised form July 17, 2020

Accepted January 9, 2021

\section{REFERENCES}

1. Ahmed TA, Ibrahim HM, Samy AM, Kaseem A, Nutan MT, Hussain MD. Biodegradable injectable in situ implants and microparticles for sustained release of montelukast: in vitro release, pharmacokinetics, and stability. AAPS PharmSciTech. 2014;15(3):772-80.

2. Phaechamud T, Setthajindalert O. Antimicrobial in-situ forming gels based on bleached shellac and different solvents. J Drug Deliv Sci Tec. 2018;46:285-93.

3. Mei L, Huang X, Xie Y, Chen J, Huang Y, Wang B, et al. An injectable in situ gel with cubic and hexagonal nanostructures for local treatment of chronic periodontitis. Drug Deliv. 2017; 24(1):1148-58.

4. Parent M, Nouvel C, Koerber M, Sapin A, Maincent P, Boudier A. PLGA in situ implants formed by phase inversion: critical physicochemical parameters to modulate drug release. J Control
Release. 2013;172(1):292-304.

5. Jouyban A, Fakhree MAA, Shayanfar A. Review of pharmaceutical applications of N-methyl-pyrrolidone. J Pharm Pharm Sci. 2010;13(4):524-35.

6. Liu H, Venkatraman SS. Cosolvent effects on the drug release and depot swelling in injectable in situ depot-forming systems. J Pharm Sci. 2012;101(5):1783-93.

7. Do MP, Neut C, Delcourt E, Seixas Certo T, Siepmann J, Siepmann F. In situ forming implants for periodontitis treatment with improved adhesive properties. Eur J Pharm Biopharm. 2014;88(2):342-50.

8. Tian Y, Shen Y, Jv M. Synthesis, characterization and evaluation of tinidazole-loaded mPEG-PDLLA (10/90) in situ gel forming system for periodontitis treatment. Drug Deliv. 2016;23(8): 2726-35.

9. Avachat AM, Dash RR, Shrotriya SN. Recent investigations of plant based natural gums and mucilages in novel drug delivery systems. Indian J Pharm Educ. 2011;45(1):86-99.

10. Phaechamud T, Lertsuphotvanit N, Praphanwittaya P. Viscoelastic and thermal properties of doxycycline hyclate-loaded bleached shellac in situ-forming gel and -microparticle. J Drug Deliv Sci Tech. 2018;44:448-56.

11. Burger P, Casale A, Kerdudo A, Michel T, Laville R, Chagnaud $\mathrm{F}$, et al. New insights in the chemical composition of benzoin balsams. Food Chem. 2016;210:613-22.

12. Hacini Z, Khedja F, Habib I, Kendour Z, Debba Z. Evaluation of antibacterial and antioxidant activities of three types of benzoin resin. Chem Eur J. 2018;9(4):408-11.

13. Boufadi YM, Soubhye J, Riazi A, Rousseau A, Vanhaeverbeek $\mathrm{M}$, Neve J, et al. Characterization and antioxidant properties of six Algerian propolis extracts: ethyl acetate extracts inhibit myeloperoxidase activity. Int J Mol Sci. 2014;15(2):2327-45.

14. Anjum SI, Ullah A, Khan KA, Attaullah M, Khan H, Ali H, et al. Composition and functional properties of propolis (bee glue): A review. Saudi J Biol Sci. 2018;26(7):1695-703.

15. Rassu G, Cossu M, Langasco R, Carta A, Cavalli R, Giunchedi $\mathrm{P}$, et al. Propolis as lipid bioactive nano-carrier for topical nasal drug delivery. Colloids Surf B Biointerfaces. 2015;136:908-17.

16. Celestino VRL, Maranhão HML, Vasconcelos CFB, Lima CR, Medeiros GCR, Araújo AV, et al. Acute toxicity and laxative activity of Aloe ferox resin. Rev Bras Farmacogn. 2013;23(2): 279-83.

17. López Z, Núñez-Jinez G, Avalos-Navarro G, Rivera G, SalazarFlores J, Ramírez JA, et al. Antioxidant and Cytotoxicological Effects of Aloe vera Food Supplements. J Food Qual. 2017; 2017:1-10.

18. Sun YN, Li W, Yang SY, Kang JS, Ma JY, Kim YH. Isolation and identification of chromone and pyrone constituents from Aloe and their anti-inflammatory activities. J Funct Foods. 2016;21:232-9.

19. Coopoosamy RM, Magwa ML. Antibacterial activity of aloe emodin and aloin A isolated from Aloe excelsa. Afr J Biotechnol. 2006;5(11):1092-4.

20. Lopez A, de Tangil MS, Vega-Orellana O, Ramirez AS, Rico M. Phenolic constituents, antioxidant and preliminary antimycoplasmic activities of leaf skin and flowers of Aloe vera (L.) Burm. f. (syn. A. barbadensis Mill.) from the Canary Islands (Spain). Molecules. 2013;18(5):4942-54.

21. Esposito E, Carotta V, Scabbia A, Trombelli L, D’Antona P, Menegatti E, et al. Comparative analysis of tetracycline containing dental gels: poloxamer- and monoglyceride-based formulations. Int J Pharm. 1996;142:9-23.

22. Phaechamud T, Mahadlek J, Chuenbarn T. In situ forming gel comprising bleached shellac loaded with antimicrobial drugs for periodontitis treatment. Mater Des. 2016;89:294-303.

23. Phaechamud T, Jantadee T, Mahadlek J, Charoensuksai P, Pichayakorn W. Characterization of antimicrobial agent loaded eudragit RS solvent exchange-induced in situ forming gels for periodontitis treatment. AAPS PharmSciTech. 2017;18(2):494- 
508.

24. Fernandez X, Lizzani-C L, Loisea A-M, Perichet C, Delbecque C. Volatile constituents of benzoin gums: Siam and Sumatra. Part 1. Flavour Fragr J. 2003;18:328-33.

25. Ramnath S, Venkataramegowda S, Singh C. Chemical composition of bee propolis collected from different regions in India by GCMS analysis. J Pharmacogn Phytochem. 2015;30(1):20517858.

26. Kažys R, Rekuvienė R. Viscosity and density measurement methods for polymer melts R. Kažys, R. Rekuvienè. Ultragarsas (Ultrasound). 2011;66(1392-2114):20-5.

27. Phaechamud T, Praphanwittaya P, Laotaweesub K. Solvent effect on fluid characteristics of doxycycline hyclate-loaded bleached shellac in situ-forming gel and -microparticle formulations. J Pharm Investig. 2017;48(3):409-19.

28. Huang S, Zhang CP, Wang K, Li GQ, Hu FL. Recent advances in the chemical composition of propolis. Molecules. 2014; 19(12):19610-32.

29. DemIRay H, EŞIZZ Dereboylu A, Yazici ZI, Karabey F. Identification of benzoin obtained from calli of Styrax officinalis by HPLC. Turk J Bot. 2013;37:956-63.

30. Camargo JA, Sapin A, Nouvel C, Daloz D, Leonard M, Bonneaux $\mathrm{F}$, et al. Injectable PLA-based in situ forming implants for controlled release of Ivermectin a BCS Class II drug: solvent selection based on physico-chemical characterization. Drug Dev Ind Pharm. 2013;39(1):146-55.

31. Xuan JJ, Balakrishnan P, Oh DH, Yeo WH, Park SM, Yong CS, et al. Rheological characterization and in vivo evaluation of thermosensitive poloxamer-based hydrogel for intramuscular injection of piroxicam. Int J Pharm. 2010;395(1-2):317-23.

32. Allahham A, Stewart P, Marriott J, Mainwaring DE. Flow and injection characteristics of pharmaceutical parenteral formulations using a micro-capillary rheometer. Int J Pharm. 2004; 270(1-2):139-48.

33. Björn A, Paula Segura de La Monja PS, Karlsson A, Ejlertsson J, Svensson BH. Rheological Characterization. Biogas. 2012:6376.

34. Cilurzo F, Selmin F, Minghetti P, Adami M, Bertoni E, Lauria $\mathrm{S}$, et al. Injectability evaluation: an open issue. AAPS PharmSciTech. 2011;12(2):604-9.

35. Rungseevijitprapa W, Bodmeier R. Injectability of biodegradable in situ forming microparticle systems (ISM). Eur J Pharm Sci. 2009;36(4-5):524-31.

36. Fathi-Azarbayjania A, Jouybanb A, Chana SY. Impact of Surface Tension in Pharmaceutical Sciences. J Pharm Pharm Sci 2009;12(2):218-28.

37. Thurein SM, Lertsuphotvanit N, Phaechamud T. Physicochemical properties of $\beta$-cyclodextrin solutions and precipitates prepared from injectable vehicles. Asian J Pharm Sci. 2018; 13(5):438-49.

38. Ansel HC, Norred WP, Rothi IL E. Antimicrobial Activity of Dimethyl Sulfoxide Against Escherichia coli, Pseudomonas aeruginosa, and Bacillus megaterium. J Pharm Sci. 1969;58(7): 836-9.

39. Machado B, Pulcino T, Silva A, Melo D, Silva R, Mendonca I Propolis as an alternative in prevention and control of dental cavity. J Apither. 2016;1(2):47-50.

40. Mašek T, Perin N, Racané L, Cindrić M, Čipčić Paljetak H, Perić $\mathrm{M}$, et al. Chemical Composition, Antioxidant and Antibacterial Activity of Different Extracts of Poplar Type Propolis. Croat Chem Acta. 2018;91(1).

41. Altemimi A, Lakhssassi N, Baharlouei A, Watson DG, Lightfoot DA. Phytochemicals: Extraction, Isolation, and Identification of Bioactive Compounds from Plant Extracts. Plants (Basel). 2017;6(4)

42. Athikomkulchai S, Awale S, Ruangrungsi N, Ruchirawat S, Kadota S. Chemical constituents of Thai propolis. Fitoterapia. 2013;88:96-100.

43. Bertolini PF, Biondi Filho O, Pomilio A, Pinheiro SL, Carvalho MS. Antimicrobial capacity of Aloe vera and propolis dentifrice gainst Streptococcus mutans strains in toothbrushes: an in vitro study. J Appl Oral Sci. 2010;20(1):32-7.

44. Silva AJ, Silva JR, de Souza NC, Souto PCS. Membranes from latex with propolis for biomedical applications. Mater Lett. 2014;116:235-8.

45. Borges JG, Carvalho RA. Orally disintegrating films containing propolis: properties and release profile. J Pharm Sci. 2015; 104(4):1431-9.

46. De Souza Ferreira SB, De Assis Dias BR, Obregon CS, Gomes CC, De Araujo Pereira RR, Ribeiro Godoy JS, et al. Microparticles containing propolis and metronidazole: in vitro characterization, release study and antimicrobial activity against periodontal pathogens. Pharm Dev Technol. 2014;19(2): $173-80$.

47. Vongsak B, Chonanant C, Machana S. In vitro cytotoxicity of Thai stingless bee propolis from Chanthaburi orchard. Walailak J Sci \& Tech. 2017;14(9):741-7.

48. Utispan K, Chitkul B, Koontongkaew S. Cytotoxic Activity of Propolis Extracts from the Stingless Bee Trigona Sirindhornae Against Primary and Metastatic Head and Neck Cancer Cell Lines. Asian Pac J Cancer Prev. 2017;18(4):1051-5.

49. Wang F, Hua H, Pei Y, Chen D, Jing Y. Triterpenoids from the Resin of Styrax tonkinensis and Their Antiproliferative and Differentiation Effects in Human Leukemia HL-60 Cells. J Nat Prod. 2006;69(5):807-10. 